\title{
An Interrogation on Newsjacking in Content Marketing
}

\author{
S.Sridevi, S.Chandramohan
}

\begin{abstract}
Newsjacking is the workmanship and study of infusing your thoughts into a breaking news story so you and your thoughts get took note. Newsjacking alludes to the act of gaining by the fame of a news story to intensify your deals and promoting achievement. Fundamentally, news is breaking each second in this insane universe of our own, and there's a time when advertisers have a one of a kind chance to ride the fame wave of a breaking story to profit their business somehow or another. Presently, the ubiquity subsides before long - maybe in hours, for the most part in days, in case you're fortunate, in weeks - however the effect of catching the story right on time to profit your business is huge ... particularly contrasted with the exertion you needed to put in to get in on the activity.
\end{abstract}

\section{INTRODUCTION}

At the point when there is news in your commercial center correspondents and investigators are searching for specialists to remark on the story. Newsjacking gets you media consideration. As the story creates progressively, purchasers become inspired by items and administrations dependent on what's going on now. Newsjacking produces potential customers and includes new clients. Newsjacking is an extraordinary method to develop your business. Newsjacking has enabled firms to grow its range of authority from neighborhood to worldwide. Our newsjacking endeavors have brought about extended crowds and connections at no other time thought was conceivable. Meetings, discourse, and at last, new customers and cases are the upbeat aftereffect of our newsjacking endeavors. In the event that you found a chance to compose a blog entry, dispatch a social mediacampaign, get press inclusion, or create a type of offers or lead gen offerin those situations, at that point you're a newsjacker - and that is an extraordinary thing to be as an inbound advertiser. In the event that you haven't known about newsjacking previously, well then this is the blog entry for you. Right away, we should separate what newsjacking is, the reason each inbound advertiser ought to do it, and exactlyhow you can do it without anyone else's help. In the event that individuals will be discussing it, and it influences our gathering of people, we ought to expound on it and getting in on the activity. However, it stretches out past just news legitimately identified with your industry. News outlets absolutely thought in this way, and the story was grabbed around the world.

Revised Manuscript Received on July 22, 2019.

S.Sridevi, Ph.D Scholar, Alagappa Institute of Management, Alagappa University, Karaikudi

Dr.S.Chandramohan, Professor, Alagappa Institute of Management, Alagappa University, Karaikudi

\section{WHY YOU SHOULD NEWSJACK}

Here's the thing about newsjacking ... to do it well, you must be snappy. That is additionally perhaps the greatest advantage of newsjacking! Advertisers frequently get so got up to speed in the subtleties of a battle or hindered by the possibility of composing a blog entry that they become deadened, and don't really wind up doinganything by any stretch of the imagination. Be that as it may, boosting advertisers out of a dormancy funk isn't the main advantage to newsjacking. It likewise yields SEO benefits, improves your image's notoriety, and drives exceptionally focused on traffic that can transform into leads and even deals - and it does everything incredibly rapidly with ease.

\section{A. How to Newsjack}

a) You're going to figure out how to newsjack, and it may resemble a ton of steps. Try not to be threatened! Newsjacking is a really basic procedure, and recall - the way to doing it effectively is considering and acting quick. So while I've broken this out into numerous means to make it simpler to process, when you do this for yourself out of the blue, you'll see exactly how quickly you travel through the procedure.

Set Up Alerts

To discover stories to newsjack, you need to always screen the news. You could spend the whole day perusing the web, or you could utilize innovation to make observing a lot simpler and less tedious! I'm expecting you incline toward the last ;- ) Set up a RSS channel that incorporates real news outlets just as industry productions that will alarm you to both common and out-of-the-case openings. Also, remember about utilizing web-based social networking, especially Twitter, as a method for discovering newsjacking openings. We utilize our own web-based social networking observing device to set up notices of terms we'd like to screen for, and maybe newsjack!

\section{c) Check Keyword Search Volume}

When you discover a story you'd like to newsjack, you'll have to make some substance around it. Before you get composing, take a couple of minutes to look into the inquiry volume around varieties of the watchword 
expression you'd like to target. Indeed, Google's calculation will compensate you for expounding on a news thing first, yet wouldn't you like to get that additional little natural lift since you focused on a variety of your watchword expression with higher hunt volume? For instance, did you realize that the expression "what is the google panda update" has a surmised worldwide month to month pursuit of 14,800, while the expression "google panda update clarification" has (wheeze!) no hunt volume? That is a decent snippet of data to have while making and streamlining your substance, and all from only a couple measly minutes of catchphrase investigate.

\section{Read About Your Topic}

I know, you need to get to the real newsjacking effectively, isn't that so? One all the more thing before you begin making content and advancing! Locate the essential wellspring of the news story, and what others have officially expounded on the news story. This is significant for two reasons: it enables you to look after creativity, and validity.

e) Consider it along these lines - if the London Fire Brigade offered their free flame preparing exercises to Kate Winslet a couple of hours after another gathering did precisely the same thing, they'd look silly and antiquated, also their exertion would be squandered. So also, on the off chance that we had composed a blog entry clarifying the Google Knowledge Graph dependent on only one news outlet's comprehension of the change, we could without much of a stretch go along inaccurate data, or at any rate not present the whole extent of the story. Locate the essential source, check what others have composed, and get a firm handle on the story before you continue to the genuine newsjacking.

Write Quickly, but Accurately

Since you're knowledgeable in the breaking story you're going to newsjack, get to composing ... furthermore, do it quick! Normally when you compose a blog entry, you may invest energy filtering through stock photography to locate the best picture to go with the post. Or on the other hand maybe you explore different avenues regarding organizing to see whether your rundown ought to be in slug or number configuration. While we praise your stickler nature, newsjacking isn't the ideal opportunity for such things - you need to be the first to react to a news story, all things considered! For whatever length of time that your substance is exact and has been perused once by a confided in partner, the nitpicky things a significant number of us normally do before distributing substance ought to be saved for some other time. g)

\section{Differentiate Yourself}

You ought to dependably infuse your very own point when you're newsjacking. Ask yourself - what makes this story intriguing to my gathering of people, explicitly? For instance, a designer could newsjack the Google Knowledge Graph story by expounding on how their calculation was built, instead of expounding on how it influences advertisers and SEOs. Or on the other hand possibly you're a bit late to the game and somebody has effectively composed your edge to the story. That doesn't mean you can't compose it better maybe you can be progressively careful, all the more clear, or give increasingly important models. When you're newsjacking, you have to give some motivation to individuals to reference your substance over the various substance out there.

Get the Word Out

The last advance to an effective newsjacking is really advertising your promoting. Indeed, you may get some common footing from natural hunt, however that by itself won't give you the power punch you needed that made you newsjack in any case. Tell individuals about your turn on the story! For instance, we share the majority of our newsjacking content on our informal organizations to broaden its range. Yet, we additionally encourage long haul associations with accomplices and writers who can help get the word out there when pertinent. All things considered, others are continually searching for delicious substance to keep their web content streaming - in the event that you can be the one to offer them a one of a kind story, you can wager they're going to give your newsjacking some inclusion.

\section{B. When to Newsjack a Story}

To newsjack the correct way, you have to comprehend the lifecycle of a news story. 


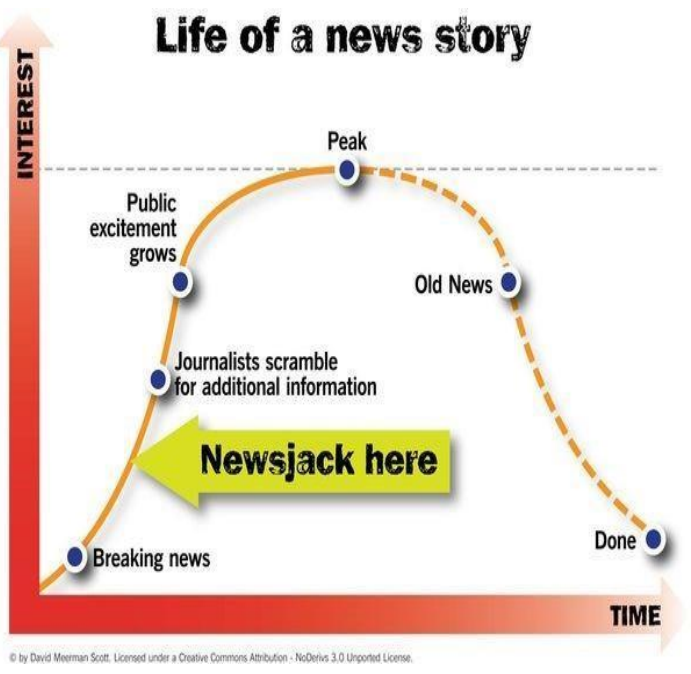

The life of a story can keep going for a considerable length of time or weeks, or it may just last a couple of hours. Obviously, timing is everything.

\section{How the life of a news story works:}

1. Breaking News: An occasion occurs. News outlets report whatever subtleties they have accessible to get their accounts out as fast as could be allowed. This is the perfect time to newsbreak.

2. The Scramble \& Excitement: Contingent upon the effect of the occasion and the underlying promotion, writers scramble to discover new data from anyplace they can. This is as yet a decent time to newsbreak in the event that you bring some new understanding or turn the story such that nobody else has.

3. The Peak: At this point, the overall population knows about the story and has heard a few twists on the topic. In the event that you effectively newsjacked the story, your substance will get the chance to ride the wave to the pinnacle.

4. Old News: The majority of the potential edges have been depleted and individuals have lost enthusiasm for the theme. There's no reason for attempting to newsjack old news.

\section{How Will Newsjacking Help My SEO (Search engine optimization)?}

As a story patterns, look traffic for catchphrases identified with that story will in general detonate. Google highlights articles about that story at the highest point of indexed lists and stories get featured by Twitter's inclining themes. When you newsjack a story at the correct time, you get in before the story crests and can catch eye while it's as yet assembling. Despite the fact that there will be intense challenge for this traffic, on the off chance that you get in sufficiently early you will get joins from different outlets that utilization your article as a source of perspective. In this way, newsjacking can give present moment and long haul SEO benefits.

\section{How to Newsjack a Story}

The primary thing you have to do is discover news to jack. There are continually going to be openings, however you need to recognize them fast enough to ride the wave. In the event that you hop on the story past the point of no return, your rivals are probably going to get the best of you, however more regrettable, the pattern is probably going to pass.

\section{HOW TO TRACK RELEVANT NEWS}

- Use Google Trends to screen inclining stories and Google Alerts to screen watchwords.

- Follow columnists and bloggers that main stories significant to your industry.

- Keep an eye on inclining hashtags on Twitter.

- Luck - be in the correct spot at the ideal time.

\section{NEWSJACKING TO-DO LIST}

- Publish a blog entry with your interpretation of the story

- Tweet about it utilizing the set up hashtag

- Directly contact columnists who may be intrigued on Twitter

- Hold a live or virtual question and answer session utilizing Periscope or Facebook Live.

What is the first step in newsjacking, and what are key factors to success?

The initial step, and the most significant one, is to build up an ongoing outlook.However, ongoing correspondence is contradictory to the super corporate worldview in which any message ought to mirror the agreement rising up out of a broad procedure. That may have worked back when open talk was basically a corporate monolog. It doubtlessly does not work in the time of online networking, nonstop news, and newsjacking. I suggest drawing up a formal order-closed down by senior administration, the PR division, and the lawful office - that sets out standards of commitment similarly that military authorities are engaged. This order should give select bleeding edge staff the opportunity and adaptability to compose a blog entry or send a media ready when all is good and well. That may be late during the evening or on an end of the week or amidst a vacation. To effectively newsjack-or battle off a newsjack-you can hardly wait for endorsement. You simply need to do it.

\section{DOWNSIDES TO NEWSJACKING}

Newsjacking is especially risky with any story that has a negative implication. At whatever point there is a chance to newsjack a story, there is a need to give some profound considered how to have a genuine bind to it, particularly if the story includes passing or decimation. You don't need to hit a grand slam each opportunity to profit by newsjacking, and you positively shouldn't endeavor to commit the majority of your substance showcasing endeavors to it. This is simply one more valuable trap to have at your disposal as a sagacious advertiser. The open doors are unending, you simply need to look out.

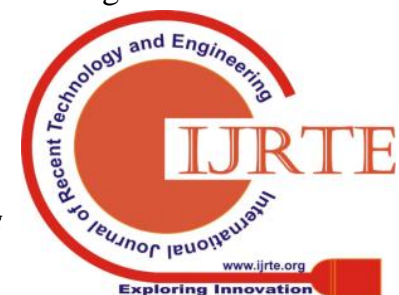




\section{REFERENCES}

1. Birkner, C. (2012). The ABCs of Affiliate Marketing, in: Coreconcepts, Marketing News Bockhorni, Markus, (n.d.), Customer Journey optimieren - $\quad$ Touchpoint-Analyse im Multichannel-Marketing; URL: http:// www.onlinemarketing-praxis.de/web-controlling/customer-journey-o ptimieren-touchpoint-analyse-im-multichannel-marketing.

2. Codourey, M. (2013). The Public Handshake, the Pushed Gossip and the Healthcare Marketing, Economics and Sociology, Vol. 6, No 2, pp. 11-27. DOI: 10.14254/2071-789X.2013/6-2/2.

3. Constantinides, E. (2002). The 4S web-marketing mix model. Electronic Commerce Research and Applications, 1(1), 57- 76

4. Gopal, R. D., Tripathi, A. K., \& Walter, Z. D. (2006). Economics of first-contact email advertising. Decision Support Systems, 42(3), 1366-1382.

5. Herget, J., Petrů, Z., Abrhám, J. (2015), City branding and its economic impacts on tourism, Economics and Sociology, Vol. 8, No 1, pp. 119-126. DOI: 10.14254/2071- 789X.2015/8-1/9.

6. Kozinets, R. V. (2002). The field behind the screen: using netnography for marketing research in online communities. Journal of marketing research, 39(1), 61-72. 